Vol.26 No.1, Juni 2020

ISSN (p): 1693-590x, ISSN (e): 2686-4711

DOI: $10.36309 /$ goi.v26i1.123

\title{
Prototipe Pembuka dan Penutup Pintu Berbasis Arduino Uno R3 dengan Bluetooth Hc-05 Menggunakan Mikro Servo
}

\author{
Kristono**1, D'jayus Noor Salim ${ }^{2}$, Rido Budi Atmojo ${ }^{3}$ \\ ${ }^{1,2}$ Program Studi Sistem Informasi, STMIK AUB, Surakarta, Indonesia \\ ${ }^{3}$ Program Studi Teknik Komputer, STMIK AUB, Surakarta, Indonesia \\ e-mail: *1kristono@stmik-aub.ac.id,2djayus.nur@stmik-aub.ac.id
}

\begin{abstract}
Abstrak
Pintu merupakan properti keamanan paling utama dalam menjaga suatu bangunan yang ada didalamnya.Setiap orang sering merasa khawatir karena semakin maraknya tindak kejahatan yang terjadi dimana-mana.

Pembuatan prototipe pembuka dan penutup pintu berbasis arduinouno $R 3$ dengan bluetooth HC-05 menggunakan mikro servoini digunakan mempermudah serta memberikan keamanan manusia untuk membuka dan menutup pintu. Tanpa harus di dilakukan secara manual dan akan memerlukan waktu dan tenaga untuk melakukan hal tersebut, maka dengan memanfaatkan prototipe pembuka dan penutup pintu berbasis arduino UNO R3 dengan bluetooth HC-05 menggunakan mikro servoakan memperpendek waktu dan menghemat tenaga.

Pintu akandipasangi sebuah motor untuk menggerakkan pintu dari jarak yang ditentukan. Dengan menggunakan transmisi bluetoothpintu akan dikendalikan oleh manusia dengan menggunakan smartphone android.
\end{abstract}

Kata kunci-Bluetooth HC-05, Arduino UNO R3, Mikro Servo, Smartphone Android

\begin{abstract}
The door is the main security property in maintaining a building that is inside it. Everyone often feels worried because of the widespread crime that occurs everywhere.

Making prototypes for openers and arduinouno R3based door closers with bluetooth HC-05 using this micro servo is used to facilitate and provide human security to open and close the door. Without having to do it manually and will require time and effort to do this, then by utilizing the prototype opening and arduino UNO R3-based door closers with bluetooth HC-05 using micro servo will shorten the time and save energy.

The door will be fitted with a motor to drive the door from a specified distance. By using a Bluetooth transmission the door will be controlled by humans using an Android smartphone.
\end{abstract}

Keywords-Bluetooth HC-05, Arduino UNO R3, Mikro Servo, Android Smartphone

\section{PENDAHULUAN}

Perkembangan Rumah merupakan salah satu kebutuhan pokok dalam kehidupan manusia. Sebagai tempat berlindung dari segala cuaca, sekaligus sebagai tempat tumbuh kembang dan bekumpulnya komunitas terkecil manusia, yaitu keluarga. Setiap keluarga yang menghuni rumah masing-masing layak mendapatkan keaman dan kenyamana untuk melangsungkan kehidupan.

Menurut berita solopos.com, seorang pemilik rumah kedapatan barang miliknya hilang. Kejadian tersebut terjadi saat rumah keadaan kosong sang pemilik rumah sedang pergi, pemilik 
rumah menyadari bahwa barang miliknya diambil seorang pencuri secara diam-diam, pencuri memasuki rumah dengan mencongkel pintu belakang rumah. Keamanan dari pencuri adalah hal yang paling penting dan paling diharapkan setiap manusia, akan tetap imenjaga keamanan dari pencuri adalah hal yang paling sulit dilakukan dan tidak lah mudah untuk dikerjakan karena keterbatasan manusia.

Namun pada kenyataan kasus pembobolan rumah pada zaman sekarang dengan mudahnya para pencuri membuka pengunci pada pintu yang terpasang hanya dengan seutas kawat atau pun dengan kunci tiruan lainya. Keahlian pencuri semakin hebat, oleh karena itu kita harus berpikir bagaimana caranya agar rumah tetap terjaga dan bebas dari para pencuri atau pembobol. Seiring berkembangnya teknologi seiring juga perkembangan manusia menciptakan sebuah alat yang mampu mencegah tindakan pencurian atau pembobolan, yaitu pintu yang mampu memberikan keamanan suatu rumah maupun kantor yang dapat akses melaui smartphone android.

Peningatan tingkat kriminalitas dan keahlian para pencuri yang semakin tinggi, penulis membuat alat pengaman pintu menggunakan smartphone android berbasi sarduino UNO yang tentunya dengan sistem keamanan yang tinggi pintu yang dapat dikendalikan secara otomatis dari jarak jauh menggunakan smartphone android. Sehingga memberikan kenyamanan pemilik rumah ketika dalam keadaan tidur mapun saat meninggalkan rumah.

Berdasarkan permasalahan yang ada untuk mengatasi tindakan kriminalitas penulis merancang dan membuat "Prototipe Pembuka dan Penutup Pintu Berbasis Arduino Uno R3 dengan Bluetooth Hc-05 Menggunakan Mikro Servo", sehingga dapat memberikan keamanan serta memudahkan pemilik rumah untuk mengendalikan pintu secara otomatis dari jarak jauh melalui smartphone android.

\section{METODE PENELITIAN}

\subsection{Blok Diagram}

Pemilihan perangkat keras (Hardware) dan perangkar lunak (software) yang merupakan implementasi sistem. Konsep dasar merupakan pedoman untuk merencanakan sesuatu dalam melakukan rancangan (desain), diman konsep ini memuat langkah-langakah dan petunjuk untuk menetukan sesuatu penunjang yang dibutuhkan dalam mendesain. Berikut ini Gambar 1 diagram blok prototipe pembuka dan penutup pintu berbasis Arduino UNO R3 dengan Bluetooth HC-05 menggunakan Mikro Servo.

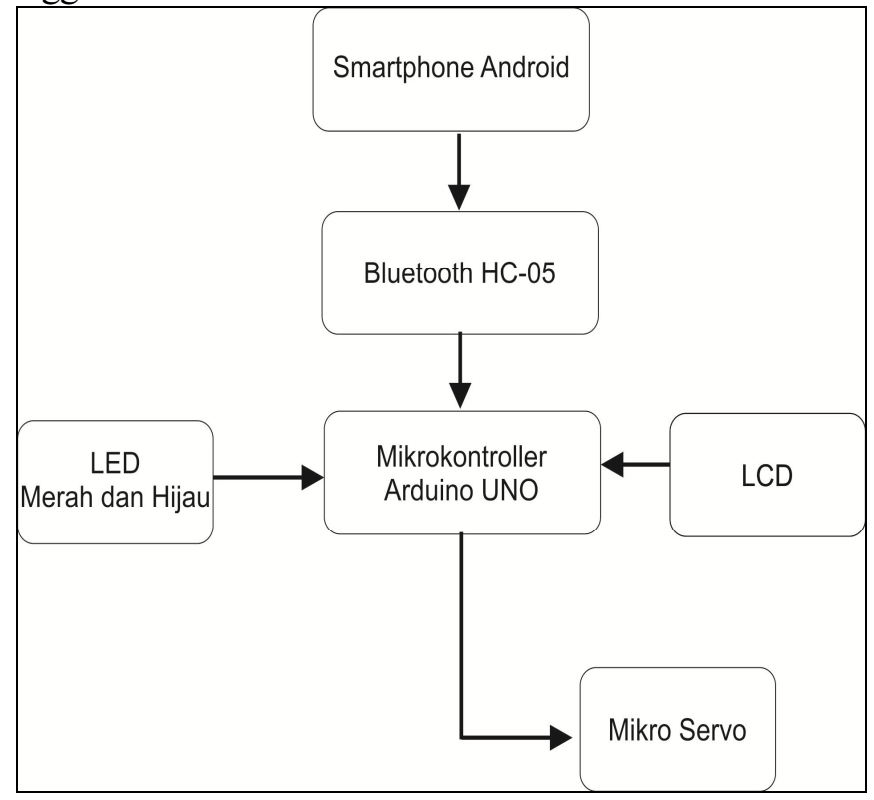

Gambar 1. Blok Diagram 


\subsection{Flowchart Sistem}

Flowchart adalah gambaran secara grafik yang terdiri dari simbol-simbol dari algoritmaalgoritma dalam suatu program yang menyatakan arah alur suatu program, diagram alir merupakan dasar dari pemrograman.

Diagram alir perlu dibuat sesuai dengan perangkat keras yang dibuat, agar program yang dibuat terstruktur dan jelas. Selain itu juga alur program yang dibuat jelas. Diagram alir pembuatan prototype sistem pengamanan pintu gerbang pada parkiran kampus dapat dilihat pada Gambar 2.

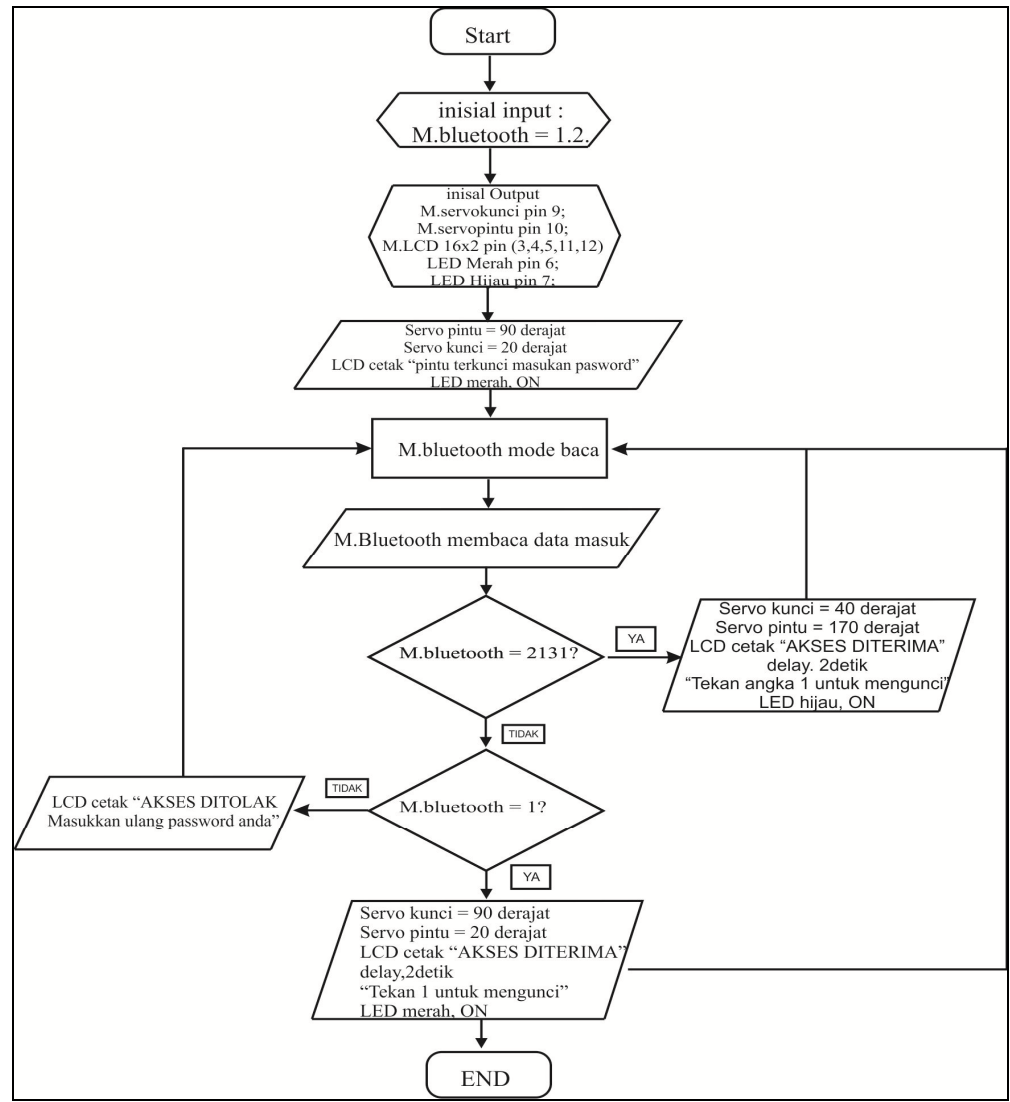

Gambar 2. Alur flowchart

\subsection{Rangkaian Alat}

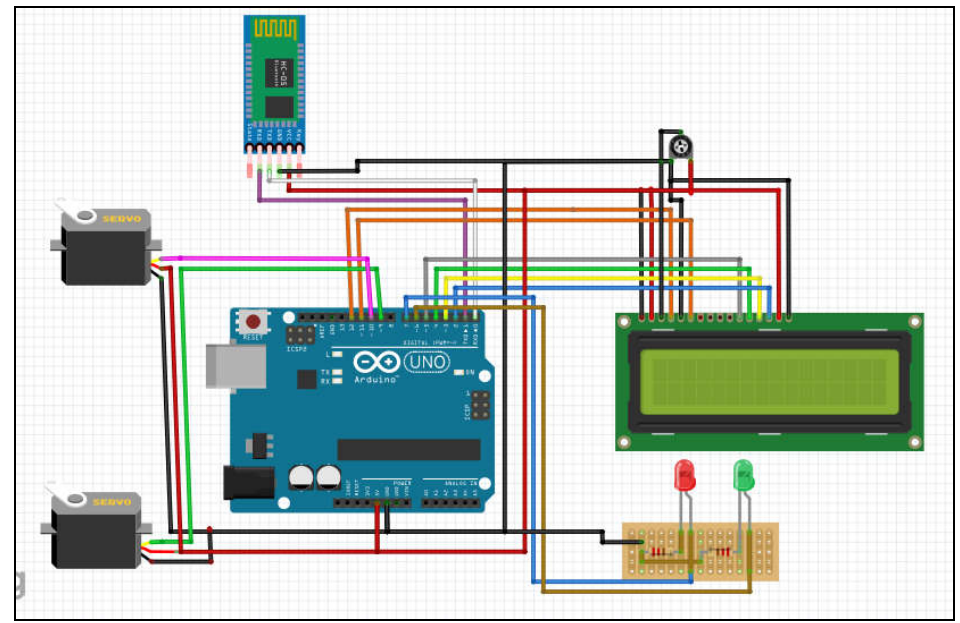

Gambar 3. Rangkaian Alat 
Rangkaian (design): yaitu tahapan untuk merancang meliputi smartphone android, bluetooth HC-05, Arduino uno, LCD (Liquid Cristal Display), Potensiometer, LED (Light Emitting Diode) dan mikro servo.

\subsection{Tampilan Menu Aplikasi}

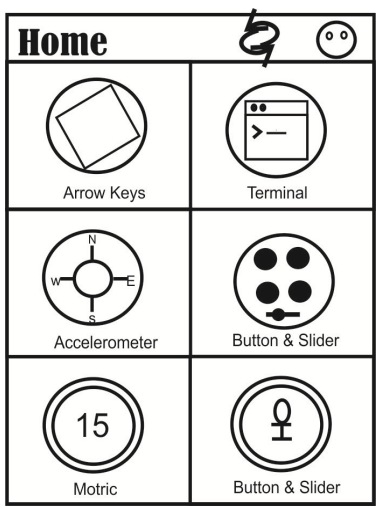

Gambar 4. Tampilan Menu Aplikasi

Pada Gambar 4 menampilakn menu pilihan remot yang akan digunakan untuk mengendalikan alat.

\subsection{Tampilan Remot Tombol}

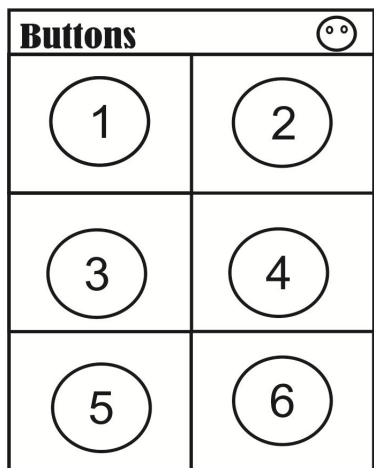

Gambar 5. Tampilan Tombol Angka

Pada Gambar 5 merupakan remot tombol yang digunakan untuk menjalankan alat.

\section{HASIL DAN PEMBAHASAN}

\subsection{Pengujian}

1. Pengujian Dan Hasil Terhadap Jarak Transmisi Bluetooth

Pengujian transmisi Bluetooth ini dilakukan dengan cara melakukan pada tempat terbuka dan tempat yang disekeliling banyak terdapat benda yang menghalangi. Dengan melakukan pengujian ini diharapkan dapat menghasilkan data jarak yang akurat pada modul Bluetooth yang digunakan sebagai penghubung antara Smartphone Android dengan Arduino.

a. Pengujian Bluetooth Pada Ruang Kosong

Pengujian dilakukan melalui aplikasi yang berjalan pada smartphone android yang dilakukan ditempat terbuka tanpa ada halangan suatu apapun. Hasilnya terdapat pada Tabel 1.

Tabel 1 Pengujian Bluetooth Pada Ruang Kosong

\begin{tabular}{|c|c|c|}
\hline Jarak & Hasil & Waktu Kerja \\
\hline 1 Meter & Sukses & 0,4 \\
\hline 2 Meter & Sukses & 0,4 \\
\hline
\end{tabular}




\begin{tabular}{|c|c|c|}
\hline 3 Meter & Sukses & 0,4 \\
\hline 4 Meter & Sukses & 0,5 \\
\hline 5 Meter & Sukses & 0,5 \\
\hline 6 Meter & Sukses & 0,5 \\
\hline 7 Meter & Sukses & 0,5 \\
\hline 8 Meter & Sukses & 0,6 \\
\hline 9 Meter & Sukses & 0,6 \\
\hline 10 Meter & Sukses & 0,6 \\
\hline 11 Meter & Sukses & 0,7 \\
\hline 12 Meter & Sukses & 0,7 \\
\hline 13 Meter & Sukses & 0,7 \\
\hline 14 Meter & Sukses & 0,8 \\
\hline 15 Meter & Terputus & 0 \\
\hline 16 Meter & Terputus & 0 \\
\hline
\end{tabular}

b. Pengujian Bluetooth pada Ruang Tertutup

Pengujian dilakukan melalui aplikasi yang berjalan pada smartphone android yang dilakukan ditempat tertutup terdapat suatu halangan. Hasilnya terdapat pada Tabel 2.

Tabel 2 Pengujian Bluetooth Pada Ruang Tertutup.

\begin{tabular}{|c|c|c|}
\hline Jarak & Hasil & Waktu Kerja \\
\hline 1 Meter & Sukses & 0,4 \\
\hline 2 Meter & Sukses & 0,4 \\
\hline 3 Meter & Sukses & 0,5 \\
\hline 4 Meter & Sukses & 0,5 \\
\hline 5 Meter & Sukses & 0,6 \\
\hline 6 Meter & Sukses & 0,6 \\
\hline 7 Meter & Sukses & 0,7 \\
\hline 8 Meter & Sukses & 0,8 \\
\hline 9 Meter & Sukses & 0,8 \\
\hline 10 Meter & Sukses & 0,8 \\
\hline 11 Meter & Terputus & 0 \\
\hline 12 Meter & Terputus & 0 \\
\hline
\end{tabular}

Pada pengujian jarak transmisi Bluetooth maka dapat disumpulkan pada ruang terbuka Bluetooth dapat bekerja secara optimal. Benda disekitar Bluetooth sangat mempengaruhi kinerja dari transmisi Bluetooth tersebut.

2. Pengujian Motor Servo

Pengujian motor servo ini harus dilakukan dengan menggunakann Smartphone Android dengan Aplikasi yang terinstal di Smartphone Android untuk memastikan bahwa motor servo telah berjalan dengan baik.
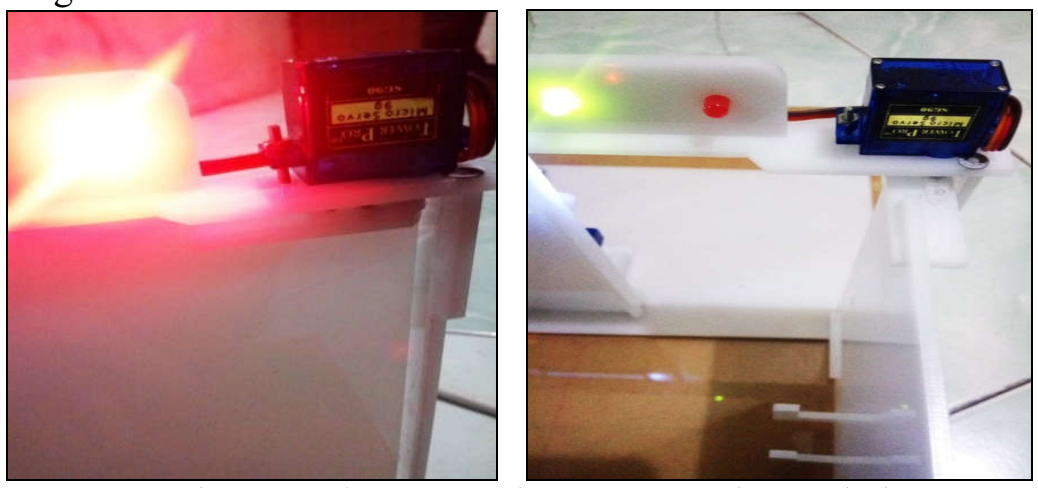

Gambar 6. Mikro Servo Pintu Tertutup dan Terbuka 
Pengujian untuk motor servo pintu ini dilakukan dengan cara mengkoneksikan Smartphone Android yang terinstal Aplikasi Arduino Bluetooth Control dengan rangakian untuk menguji motor servo sehingga dapat mengetahui bahwa motor servo tersebut dalam kondisi baik. Hasil pengujian terdapat pada Tabel 3 .

Tabel 3 Pengujian Mikro Servo Pintu

\begin{tabular}{|c|l|l|}
\hline NO & \multicolumn{1}{|c|}{ Nama Alat } & \multicolumn{1}{c|}{ Keterangan } \\
\hline 1 & $\begin{array}{l}\text { Mikro Servo Pintu } \\
\text { Tertutup }\end{array}$ & $\begin{array}{l}\text { Pintu dalam keadaan tertutup menunjukkan } \\
\text { mikro servo bekerja dengan baik dan } \\
\text { LEDmenyala berwarna merah. }\end{array}$ \\
\hline 2 & $\begin{array}{l}\text { Mikro Servo Pintu } \\
\text { Terbuka }\end{array}$ & $\begin{array}{l}\text { Pintu dalam keadaan terbuka menunjukkan } \\
\text { mikro servobekerja dengan baik dan LED } \\
\text { menyala berwarna hijau. }\end{array}$ \\
\hline
\end{tabular}
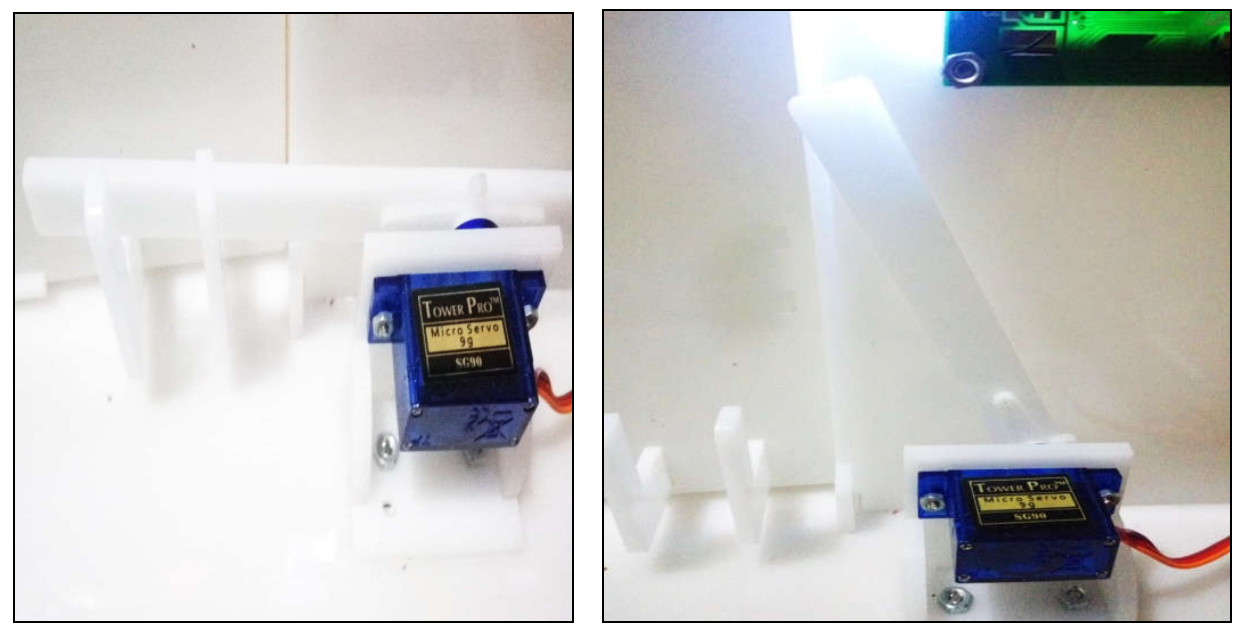

Gambar 7. Mikro Servo Kunci Tertutup dan Terbuka

Pengujian untuk motor servo kunci ini dilakukan dengan cara mengkoneksikan Smartphone Android yang terinstal Aplikasi Arduino Bluetooth Control dengan rangakian untuk menguji motor servo sehingga dapat mengetahui bahwa kinerja motor servo kunci tersebut dalam kondisi baik. Hasil pengujian kinerja motor servo kunci dapat diihat pada Tabe 4.

Tabel 4. Pengujian Mikro Servo Kunci

\begin{tabular}{|c|l|l|}
\hline NO & \multicolumn{1}{|c|}{ Nama Alat } & \multicolumn{1}{c|}{ Keterangan } \\
\hline 1 & $\begin{array}{l}\text { Mikro Servo Kunci } \\
\text { Tertutup }\end{array}$ & $\begin{array}{l}\text { Kunci dalam keadaan tertutup menunjukkan } \\
\text { mikro servo bekerja dengan baik dan } L E D \\
\text { menyala berwarna merah. }\end{array}$ \\
\hline 2 & $\begin{array}{l}\text { Mikro Servo Kunci } \\
\text { Terbuka }\end{array}$ & $\begin{array}{l}\text { Kunci dalam keadaan terbuka menunjukkan } \\
\text { mikro servobekerja dengan baik dan } L E D \\
\text { menyala berwarna hijau. }\end{array}$ \\
\hline
\end{tabular}

Setelah melakukan pengujian Mikro Servo Pintu dan Mikro servo Kunci dapat diketahui hasilnya bahwa sistem kendali Mikro Servo Pintu dan Mikro Sevo Kunci masih dalam keadaan baik dan $L E D$ menunjukkan bahwa kinerja Mikro Servo masih bejalan normal.

\subsection{Implementasi}




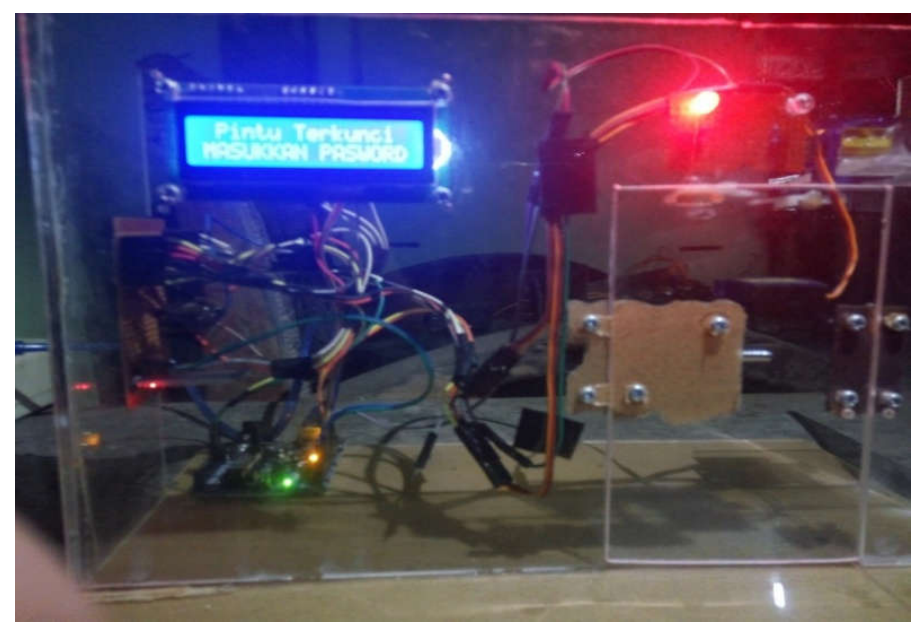

Gambar 8 Bentuk Rangkaian Pintu Tertutup

Pada Gambar 8 pintu masih tertutup dan lampu LED merah masih menyala dan $L C D$ menunjukkan bahwa pintu terkunci masukkan pasword.

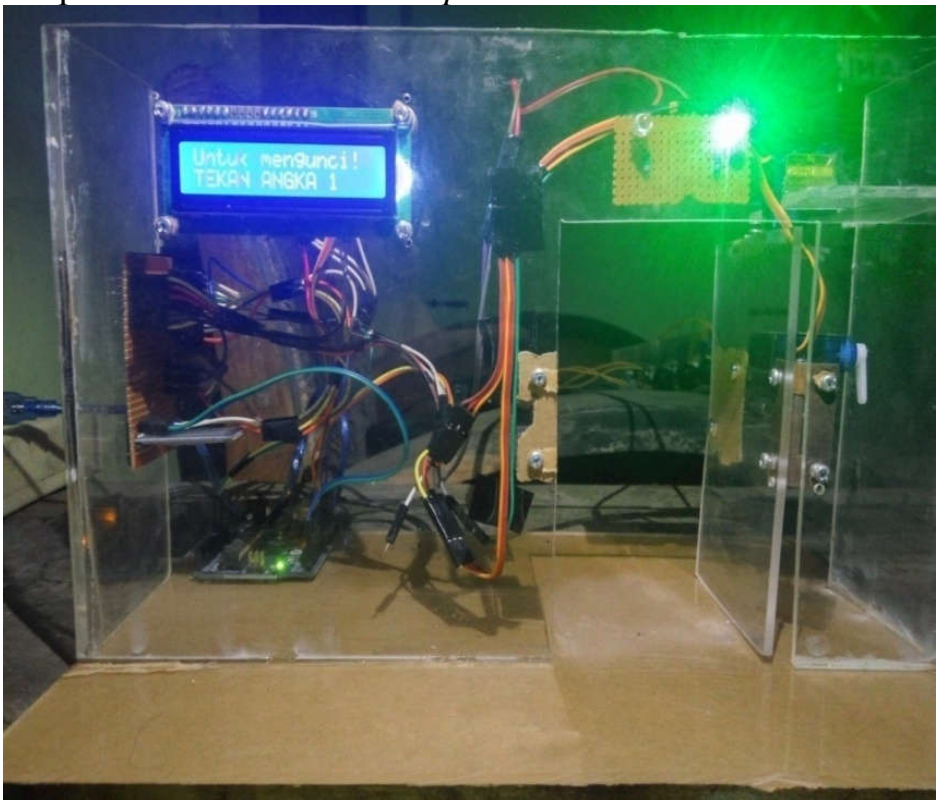

Gambar 9 Bentuk Rangkaian Pintu Terbuka

Pada Gambar 9 pintu keadaan terbuka dan lampu LED menyala berwarna hijau $L C D$ menunjukkan bahwa untuk mengunci tekan tombol 1.

\subsection{Pembahasan}

Pengujian alat secara keseluruhan dilakukan untuk mengetahui apakah alat yang telah dibuat telah berfungsi sesuai dengan yang diharapkan. Pengujian dilakukan dengan menghidupkan alat dengan cara mengkoneksikan ke Smartphone Android. Setelah semua terkoneksi maka alat ini bisa dijalankan dengan Aplikasi Bluetooth Control. Dari hasil percobaan yang telah dilakukan, alat yang dibuat memiliki respon yang baik dimana ketika kita melakukan proses input di aplikasi maka kita bisa mengetahui bahwa alat tersebut bekerja sesuai yang diharapkan.

Cara kerja alat ini adalah ketika kita mengkoneksikan Bluetooth HC-05 dengan smartphone android mikro servo akan bergerak secara otomatis menandakan bahwa smartphone telah terkoneksi dengan Bluetooth $\mathrm{HC}-05$, kemudain kita menginputkan password melalui aplikasi Bluetooth Controler ketika inputan benar maka LCD akan memunculkan karakter "Benar". 
Setelah melakukan pengujian terhadap alat ini secara keseluruhan, terdapat beberapa kesimpulan yaitu dengan adanya alat pengaman pintu menggunakann smartphone android berbasi arduino UNO yang tentunya dengan sistem keamanan yang tinggi pintu yang dapat dikendalikan secara otomatis dari jarak jauh menggunakann smartphone android mampu menggurangi tindakan kriminalitas dan pembobolan rumah. Sehingga memberikan kenyamanan pemilik rumah ketika dalam keadaan tidur maupun saat meninggalkan rumah.

\section{KESIMPULAN}

Berdasarkan hasil penelitian dan analisa yang dilakukan terhadap prototipe pintu berbasis mikrokontroler Arduino Uno R3 via Bluetooth Aplikasi Android, dapat ditarik kesimpulan sebagai berikut:

1. Prototipe telah berhasil dirancang dengan gabungan dari Mikrokontroler sebagai pengendali pusat, Android sebagai input perintah, Bluetooth sebagai media komunikasi, Mikro Servo sebagai penggerak pintu.

2. Secara matematis dari hasil pengujian Mikro Servo Model SG90, beban yang masih sanggup digerakkan oleh Mikro Servo sebesar 9 gram dengan kecepatan reaksi terbesar yang tercatat 0.1 detik / 60 derajat (4,8v tanpa beban) pada tegangan 4,48 Volt.

3. Jarak transmisi maksimum dari modul bluetooth $\mathrm{HC}-05$ ke bluetooth smartphone android yang terukur pada ruang terbuka dapat terkoneksi sejauh20 meter dengan rata-rata waktu eksekusi kurang dari 1 detik.

4. Aplikasi pengendali berbasis android dikembangkan menggunakan program App Module Bluetooth. Aplikasi bernama "Arduino bluetooth controller" dapat diinstal dan berjalan dengan baik pada smartphone Android baik dari versi 4.04 Ice Cream Sandwich hingga versi 6.0 Marshmallow.

\section{SARAN}

Dari hasil merangkai dan membuat alat yang telah terealisasi tentunya masih terdapat beberapa kekurangan, untuk itu diperlukan pengembangan pada perancangan selanjutnya. Berikut merupakan beberapa saran yang menjadi acuan untuk dapat dikembangkan, antara lain:

1. Memandukan sistem biometric pengolahan citra, seperti pemindaian sidik jari (fingerprint scanner), pendeteksi wajah (face-log-on), dan pendeteksi mata (eyes scanner).

Merealisasikan prototype dengan ukuran model pintu sebenarnya.

2. Ada baiknya untuk alat ini dapat diperbanyak, agar dapat membantu kehidupan manusia, dari tindakan kejahatan.

\section{DAFTAR PUSTAKA}

[1] Amar Magrub, Restiana Rahayu, "Sistem Keamanan Kunci Pintu Berbasis Android" skripsi. Jurusan Teknik Elektro Fakultas Teknik Universitas Sultan Ageng Tirtayasa Banten.

[2] Anggar Sadewo, "Perancang Pengendali Rumah Menggunakan Samrtphone Android dengan Koneksi Bluetooth" Progam Studi Informatika Universitas Brawijaya.

[3] Hendra Maryanto. "Pembuatan Prototipe Pintu Otomatis Satu Arah Berbasis Mikrokontroler Atmega 8535 Menggunakan Double IR" Surakarta: Universitas Sebelas Maret. 2010.

[4] http://amalbastian.blogspot.com/2009/12/teknik-teknik-pengumpulan-data.html

[5] http://www.catatanrobert.com/tahapan-dalam-metodologi-penelitian

[6] http:/tugastisi.blogspot.com/2015/06/studi-literatur-adalah.html 
[7] Ilearning "Pengertian Arduino Uno" http://ilearning.me/sample-page-162/arduino/ pengertian-arduino-uno/,(18 Desember 2015)

[8] Splashtronic "Pengertian Bluetooth HC-05" https://splashtronic.wordpress.com/2012/05/13/hc-05-bluetooth-to-serial-module/, (13 Mei 2012)

[9] Trikueni"Pengertian Motor Servo" http://trikueni-desain-sistem.blogspot.co.id /2014/03/Pengertian-Motor-Servo.html/, (19 Maret 2014)

[10] Wilfrid Sahputra Girsang, Fakhruddin Rizal Batubara, ST. MTI. "Perancangan Dan Implementasi Pengendali Pintu Pagar Otomatis Berbasis Arduino" Medan: Universitas Sumatera Utara (USU). 2010.

[11] Yogie El Anwar, Noer Soedjarwanto, Ageng Sadnowo Repelianto. "Prototype Penggerak Pintu Pagar Otomatis Berbasis Arduino Uno ATMEGA 328P dengan Sensor Sidik Jari" Bandar Lampung: Universitas Lampung. 2012. 